represent a full range of workers in this field, both scientists and practising clinicians. Their individual papers are presented, a few of these discuss current concepts in a review format, but most report individual research work with a marked clinical bias. Discussion from the floor of the meetings is also recorded.

The first section is concerned with the structure and function of the cells themselves, involving a discussion of the chemical nature of their contents and their importance in hypersensitivity reactions and in the regulation of connective tissue function. A small series of papers on the mode of action of sodium cromoglycate follows and the bulk of the volume is then devoted to sections on the role of the mast cell in respiratory disease, food allergy, eye, skin and ear, nose and throat diseases, and in inflammatory bowel disorders. Each of these parts contains papers on the relationship of mast cells to pathogenesis, making a diagnosis of an allergic disorder and the place of elimination diets and drug therapy in management. Inevitably there is repetition but this is not a book which will be read from cover to cover. The clinician in the relevant field will find much to note if he is prepared to move from paper to paper, scanning the speculations arising from the basic scientific work with interest. The book is well presented and contains an unusually extensive index which is, unfortunately, not always accurate. The proceedings have been published with commendable speed and represent a unique record of current work. References abound and the clear type is well supported by large figures, diagrams, black and white and colour plates. Although basically a reference work, it is a record of a meeting where the impact of basic knowledge on the clinical diagnosis and management of allergy was emphasized and as such it will have an appeal to a wide audience.

\section{The Tuberculin Test in Clinical Practice. An illustrated guide.}

By Maxwell Caplin. Pp. xi +84 , illustrated. Ballière Tindall, London, 1980. Paperback $£ 5.75$.

This must surely be the most comprehensive and exhaustive review of the tuberculin test and, since it is beautifully written, it must also be the most readable. Following the historical introduction, there are chapters on the Mantoux, Heaf and Tine tests; false-negative and -positive reactions: and its value in epidemiology, chemoprophylaxis, in tuberculosis and other conditions.

This account is written from the viewpoint of a chest physician interested in tuberculosis, and as such it is a splendid review of the subject. What a pity that he is not interested in immunology and the thymus-mediated $\mathrm{T}$ cells, for the tuberculin test is nowadays a bedside skin test for poor cellular immunity. The author devotes only 9 lines to cancer, which deserves a chapter on its own. The index does not mention levamisole, which is a potent stimulator of the $\mathrm{T}$ cells responsible for tuberculin hypersensitivity. But all of this will surely appear in the second edition. This edition is for the Third World, but the author must be persuaded to bring us up to date for the Fourth World. This test is too important to be abandoned at this stage of its evolution. Dr W. F. Wheeler, like the author, must also be congratulated for the most elegant illustrations.

\section{Progress in Geriatric Day Care}

By J. C. Brocklehurst and J. S. Tucker. Pp. 204. King Edward's Hospital Fund for London, London. 1980. $£ 7.00$.

This is a very comprehensive review of all aspects of geriatric day hospitals. The book is readable and interesting, opening with an outline of the literature, and history of day hospitals, and proceeding with accounts of the work-load encountered, policies, attitudes of patients, staff and relatives, design of Units, problems of transport, and costs. The benefits and disadvantages of day hospitals are carefully discussed with advice and very practical suggestions. This book is essential reading for all physicians responsible for planning or running a day hospital for the elderly.

\section{Psychopathology - its Causes and Symptoms}

By F. Kraupl Taylor. Revised edition. Pp. ix +362. Quartermaine House, Sunbury-on-Thames, Middlesex, 1979. $£ 9.50$ (cloth) $£ 5.50$ (paper).

This is the revised edition of a book first published in 1966. The cover is somewhat deceptive in that it gives the book the appearance of being 'heavy' but this is a good example of the old adage, 'Never judge a book by its cover'. The back cover states, 'The book will appeal not only to students and workers in the realm of psychiatry, psychology and social work, but also to the informed layman'. This is likely to be quite true. The reviewer would certainly recommend this book to undergraduates and postgraduates.

There are 4 parts, the last of which is entitled 'Recent Developments' and includes chapters on genetics, the XYY syndrome, PKU and pseudo-hallucinations, which are interesting and somewhat surprising topics for such a book. It is very good value for money.

\section{Topical Steroid Treatment for Asthma and Rhinitis}

Edited by N. Mygind and T. J. H. Clark. Pp. $\mathrm{x}+188$, illustrated. Baillière Tindall, London, 1980. $£ 9.50$

What an interesting fusion of Danish and British editorship, with contributions by experts from Canada (14), United Kingdom (7), Sweden (3), and one apiece from Denmark, Israel and Japan! This book has been written for clinicians who need a substantial review of topical steroid therapy in asthma and rhinitis. The greater part of this book concerns beclomethasone dipropionate, but other topical corticosteroids are also mentioned. It is a mine of information for chest physicians, allergists, immunologists, ear nose and throat surgeons, and paediatricians. 